\title{
Improvement of Biological Time-of-Flight- Secondary Ion Mass Spectrometry Imaging with a Bismuth Cluster Ion Source
}

\author{
David Touboul \\ Institut de Chimie des Substances Naturelles, CNRS, Gif-sur-Yvette Cedex, France \\ Felix Kollmer and Ewald Niehuis \\ ION-TOF GmbH, Gievenbecker Weg 15, 48149 Münster, Germany \\ Alain Brunelle and Olivier Laprévote \\ Institut de Chimie des Substances Naturelles, CNRS, Gif-sur-Yvette Cedex, France
}

\begin{abstract}
A new liquid metal ion gun (LMIG) filled with bismuth has been fitted to a time-of-flightsecondary ion mass spectrometer (TOF-SIMS). This source provides beams of $\mathrm{Bi}_{n}^{q+}$ clusters with $n$ $=1-7$ and $q=1$ and 2 . The appropriate clusters have much better intensities and efficiencies than the $\mathrm{Au}_{3}^{+}$gold clusters recently used in TOF-SIMS imaging, and allow better lateral and mass resolution. The different beams delivered by this ion source have been tested for biological imaging of rat brain sections. The results show a great improvement of the imaging capabilities in terms of accessible mass range and useful lateral resolution. Secondary ion yields $Y$, disappearance cross sections $\sigma$, efficiencies $E=Y / \sigma$, and useful lateral resolutions $\Delta L$ have been compared using the different bismuth clusters, directly onto the surface of rat brain sections and for several positive and negative secondary ions with $\mathrm{m} / \mathrm{z}$ ranging from 23 up to more than 750 . The efficiency and the imaging capabilities of the different primary ions are compared by taking into account the primary ion current for reasonable acquisition times. The two best primary ions are $\mathrm{Bi}_{3}^{+}$and $\mathrm{Bi}_{5}^{2+}$. The $\mathrm{Bi}_{3}^{+}$ ion beam has a current at least five times larger than $\mathrm{Au}_{3}{ }^{+}$and therefore is an excellent beam for large-area imaging. $\mathrm{Bi}_{5}^{2+}$ ions exhibit large secondary ions yields and a reasonable intensity making them suitable for small-area images with an excellent sensitivity and a possible useful lateral resolution <400 nm. (J Am Soc Mass Spectrom 2005, 16, 1608-1618) ( 2005 American Society for Mass Spectrometry
\end{abstract}

A mong the methods aiming to determine the spatial distribution of substances in biological tissues, imaging mass spectrometry with matrix-assisted laser desorption ionization (MALDI) or with cluster secondary ion mass spectrometry (clusterSIMS) are two similar techniques that have several advantages. These methods do not need the use of any chemical labeling and make possible, in only one single data acquisition, the direct localization of a great variety of different biological compounds on the surface of a tissue sample. The localization of different biomarkers, consequently, can be correlated to their biological significance. MALDI-MS imaging was introduced a few years ago by R.M. Caprioli and coworkers [1,2] and now is used and also improved by several groups [3-7]. With commercial MALDI-TOF mass spectrometers, the lateral resolu-

Published online August 22, 2005

Address reprint requests to Dr. Alain Brunelle, Institut de Chimie des Substances Naturelles, CNRS Av. de la Terrasse, 91198 Gif-sur-Yvette Cedex, France. E-mail: Alain.Brunelle@icsn.cnrs-gif.fr tion is generally limited by the laser spot size, which is on average about $50 \mu \mathrm{m}$. This method enables the identification of, directly on a tissue sample, regions where proteins are located [2], but also, depending mainly on the matrix coating used, ions in different mass ranges such as phospholipids [7] or drugs [8].

Biological TOF-SIMS imaging has a long history and has been successfully used by examining the intensities of low mass fragment ions (particularly using isotopically labeled species). The state of the art was recently reviewed by Belu et al. [9], Pacholski and Winograd [10], and in the book of Vickerman and Briggs [11]. There are many ways to prepare biological samples, such as freeze drying, sectioning, and mounting in a polymer and freeze fracturing. For each of these techniques, the ionization process may be different. Nevertheless, TOF-SIMS biological imaging suffered until recently from the poor secondary molecular ion production efficiency of the traditional gallium or indium LMIGs [12, 13]. The imaging capabilities of TOF-SIMS instruments on real biological samples were generally 
limited to low mass ions such as the phosphocholine head group at $\mathrm{m} / \mathrm{z}$ 184. A first important breakthrough has come recently by the addition of gold cluster LMIGs [14] to TOF-SIMS instruments. Mouse brain TOF-SIMS images were obtained with pixel sizes of a few micrometers or less, in positive and negative ion modes and with extended mass ranges, showing specific images of ions arising from cholesterol, fatty acids, sulfatides, phosphatidylinositols, or even triglycerides [15, 16]. Using model mice with Duchenne muscular dystrophy [17], many negative ions in degenerating and regenerating cells in the neighborhood of a destructured area have been imaged on the surface of a muscle tissue section. Nevertheless, the primary ion currents that can be obtained with focused $\mathrm{Au}_{3}^{+}$beams are still low and the data acquisition time with a reasonable primary ion dose density is still rather long, especially for large-area imaging. In addition, the ions are emitted with a broad kinetic energy distribution that limits the achievable lateral resolution and mass resolution. Another possibility is the use of MALDI matrix coatings (matrix-enhanced secondary ion mass spectrometry [ME-SIMS]) $[18,19]$ in TOF-SIMS imaging. Although the use of this method certainly increases the production of some secondary ions such as cholesterol, it seems that the signal enhancement could depend on the chemical structure of the secondary ion. In addition, the interpretation of the ME-SIMS spectra could be more difficult because of the presence of matrix ion peaks, which can interfere with ion peaks from the sample itself. Further, because the lateral resolution is limited to the size of the matrix crystals, generally of the order of several micrometers, the matrix deposition procedure is critical. Sample surface coating by a thin gold or silver layer [20] can increase the sensitivity of TOF-SIMS imaging. This coating method does not seem to restrict the lateral resolution, but the spectra are modified because of the metal cationization of some specific secondary ions.

In a second instrumental attempt to improve the sensitivity of TOF-SIMS, recently, it has been established that an LMIG can be operated with bismuth instead of gold [21]. The author showed that the bismuth ion emission is much more intense than the gold, and that the spatial and time focusing of the bismuth cluster beams is also better. In addition, a wider variety of ion beams could be obtained, with heavy clusters having up to seven atoms and also doubly charged ion species. Consequently, the objective of the present work has been to test this new cluster ion source for biological sample imaging.

\section{Experimental Procedures}

\section{Mass Spectrometry and Imaging Mass Spectrometry}

All the experiments described in the present paper have been performed using a standard commercial TOF-
SIMS IV (ION-TOF GmbH, Münster, Germany) [22] reflectron-type TOF mass spectrometer located at the Institut de Chimie des Substances Naturelles at Gif-surYvette (France). The primary ion source is a bismuth LMIG, which delivers $\mathrm{Bi}_{n}^{q+}$ bismuth cluster ions, with $n=1-7$ and $q=1-2$. The kinetic energy of these ions is $25 \mathrm{q} \mathrm{keV} \mathrm{(25} \mathrm{keV} \mathrm{for} \mathrm{singly} \mathrm{charged} \mathrm{ions} \mathrm{and} 50 \mathrm{keV}$ for doubly charged ions). The angle of incidence is $45^{\circ}$.

A first setting mode of the primary ion column, which was used for most of the images shown in the present paper, ensures the three following features: a good spot size, excellent pulse duration for high mass resolution, and high currents. A three-lens ion column focuses the ion beam on the target plane to a spot having a typical size of $\sim 2 \mu \mathrm{m}$. A double blanking plate system gives primary ion mass selection with repetition rates up to $50 \mathrm{kHz}$. The primary ion currents, which are measured using a Faraday cup located on the grounded sample holder, are $1 \mathrm{pA}\left(\mathrm{Bi}_{1}^{+}\right), 0.34 \mathrm{pA}\left(\mathrm{Bi}_{3}^{+}\right), 0.185 \mathrm{pA}$ $\left(\mathrm{Bi}_{3}^{2+}\right), 0.045 \mathrm{pA}\left(\mathrm{Bi}_{5}^{+}\right), 0.044 \mathrm{pA}\left(\mathrm{Bi}_{5}^{2+}\right)$, and $0.004 \mathrm{pA}$ $\left(\mathrm{Bi}_{7}^{+}\right)^{\circ} \mathrm{at}^{\circ} 10^{\circ} \mathrm{kHz}^{\circ}\left(\text { Figure }^{\circ} 1\right)^{\circ} .^{\circ} \mathrm{A}^{\circ}$ bunching $^{\circ}$ system ${ }^{\circ}$ gives pulse durations of $0.7 \mathrm{~ns}$ for $\mathrm{Bi}_{1}^{+}$and $\mathrm{Bi}_{3}^{2+}$ and of $\sim 1.0 \mathrm{~ns}$ for the other clusters, which ensures sufficiently short pulses for TOF analysis with a mass resolution exceeding $M / \Delta M=10^{4}$ (full width half maximum [FWHM]) at $\mathrm{m} / \mathrm{z}>500$.

Another operating mode can be used, which delivers beam sizes of $\sim 150-250 \mathrm{~nm}$ (depending on the chosen primary ion species). In this last case, the ion beam can not be bunched and the pulse duration is $20-100 \mathrm{~ns}$, ensuring only a nominal mass resolution. A detailed description of the different setting modes of the ion column ${ }^{\circ}$ can $^{\circ}$ be $^{\circ}$ found ${ }^{\circ}$ elsewhere ${ }^{\circ}[23]$.

The effective ion flight path is about $2 \mathrm{~m}$, the reflectron is a single stage model (first-order compensation). The secondary ions are accelerated to a kinetic energy of $2 \mathrm{keV}$ and are postaccelerated to $10 \mathrm{keV}$ before hitting a hybrid detector made of a single microchannel plate followed by a scintillator and a photomul-

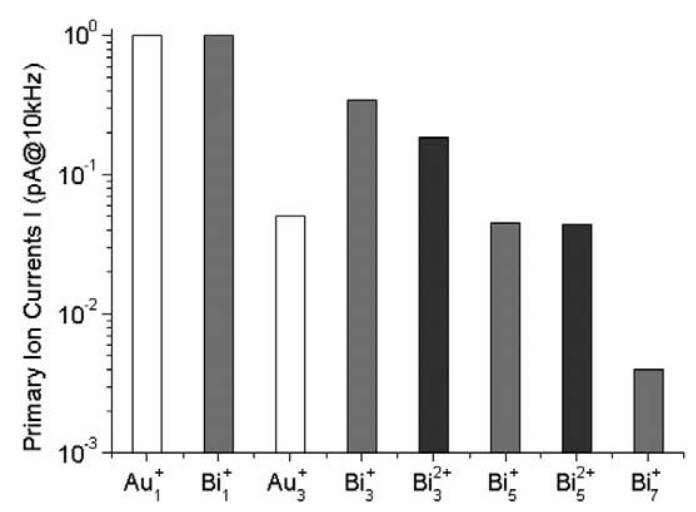

Figure 1. Bismuth cluster ion currents, measured using a Faraday cup located on the grounded sample holder at $10 \mathrm{kHz}$. The measured values have been divided by two for the doubly charged ions. Gray bars are for singly charged ions; black bars are for doubly charged ions. The white bars indicate the gold cluster ion currents that can be obtained under the same conditions. 
tiplier. TOF mass spectra are recorded using a 512multistops time-to-digital converter having a minimum bin size of $50 \mathrm{ps}$. The mass calibration of the spectra was always internal, using $\mathrm{H}^{+}, \mathrm{C}^{+}, \mathrm{CH}^{+}, \mathrm{CH}_{2}^{+}, \mathrm{CH}_{3}^{+}$, and $\mathrm{C}_{3} \mathrm{H}_{2}^{+}$ion peaks in positive ion mode and $\mathrm{H}^{-}, \mathrm{C}^{-}, \mathrm{CH}^{-}$, $\mathrm{CH}_{2}^{-}, \mathrm{C}_{2}^{-}, \mathrm{C}_{3}^{-}, \mathrm{C}_{4}^{-}$, and $\mathrm{C}_{4} \mathrm{H}^{-}$ion peaks in negative ion mode. Mass accuracies were always better than a few parts per million.

The analyzed surface can be checked at any time by the operator with the help of an integrated video camera. A low-energy electron flood gun is always activated between two pulses of the primary ion beam to neutralize any charge on the surface of the samples.

For yield and damage cross section measurements, the minimum irradiation time was $1200 \mathrm{~s}$, over an irradiated area of $100 \times 100 \mu \mathrm{m}^{2}$, ensuring a minimum primary ion dose density of $10^{12}$ ions $\cdot \mathrm{cm}^{-2}$.

Two modes of image acquisition have been used:

1. Images with fields of view of $256 \times 256 \mu \mathrm{m}^{2}$ are performed without sample stage movement just by rastering the primary ion beam. For most of the images, the ion gun mode is the one offering the best pulse duration with a moderate focus of $\sim 2 \mu \mathrm{m}$ and good intensities (see aforementioned data). The number of pixels was consequently chosen as $256 \times$ 256 to have pixel sizes of $1 \times 1 \mu \mathrm{m}^{2}$. The number of shots per pixel, and consequently the acquisition time, were adjusted for each kind of primary ion to always have the same primary ion dose density of $10^{12}$ ions $\cdot \mathrm{cm}^{-2}$. For only one image another ion gun mode was chosen, which delivers an ion beam size of $\sim 250 \mathrm{~nm}$. In this case the image was acquired with a field of $55.7 \times 55.7 \mu \mathrm{m}^{2}$ and the number of pixels was $256 \times 256$, and compressed during the data processing to $128 \times 128$ pixels for a final pixel size of $435 \times 435 \mathrm{~nm}^{2}$. This pixel size value is chosen because it is close to useful lateral resolution, which is described and measured later in this study for the same ion of cholesterol.

2. Large-area analyses $\left(18 \times 18 \mathrm{~mm}^{2}\right)$ have been performed using the same LMIG conditions and the so-called stage scan. In this mode the sample is continuously moved by the sample stage. The repeatability of the movement is better than $5 \mu \mathrm{m}$ and therefore does not limit the lateral resolution. To scan the whole surface area, the primary ion beam is rastered over the area of an individual pixel. The number of pixels was $256 \times 256$, each pixel having a size of $70 \times 70 \mu \mathrm{m}^{2}$. The number of ion beam shots per pixel and the subsequent acquisition time were adjusted for each primary ion to always have the same primary ion dose density of $10^{9}$ ions $\cdot \mathrm{cm}^{-2}$.

The name of the compounds or the $m / z$ value of the peak centroid, the maximal number of counts in a pixel (mc), and the total number of counts (tc) are written below each image. The color scales correspond to the interval $[0, \mathrm{mc}]$.

\section{Terms and Definitions}

To compare the efficiency for both spectroscopy and imaging purposes of the ion generation process under the different $\mathrm{Bi}_{n}^{q+}$ bombardment, the following values were determined directly from the tissue sections: secondary ion emission yield $Y$, disappearance cross section $\sigma$, secondary ion generation efficiency $E$, specific data rate $R$, and useful lateral resolution $\Delta L$. The values are $^{\circ}$ defined ${ }^{\circ}$ as $^{\circ}$ follows ${ }^{\circ}[24]$ :

1. Secondary ion emission yields $Y$ are calculated as the area of the peak of interest (number of detected ions) divided by the number of primary ions having impinged the surface during the acquisition of the spectrum.

2. Disappearance cross section $\sigma: N(t)=N(t=0)$. $\exp (-\sigma I t / A e)$

where $N(t)$ is the number of detected particles at time $t$, $N(t=0)$ is the number of detected particles at time $0, I$ is the primary ion current, $A$ is the bombarded area, $e$ is the elemental charge, and $\sigma$ is the mean area damaged by one primary ion and is a parameter depending on the respective secondary ion species under consideration.

3. Secondary ion efficiency $E: E=Y / \sigma ; E$ is the number of detected secondary ions of a given species per damaged area. This value accounts for the entire analysis process, also including the analyzer transmission and the detector efficiency.

4. Specific data rate for the species $\mathrm{Bi}_{n}^{q+}$ is defined as $R\left(\mathrm{Bi}_{n}^{q+}\right)=Y_{\mathrm{Bi}_{n}^{q+}} I_{\mathrm{Bi}_{n}^{q+}}$. It is named "specific" because it depends on both the primary and the secondary ions. This parameter is particularly important for large-area analysis, while the secondary ion efficiency accounts more for small areas.

5. Relative specific data rate

$$
R_{B i_{1}^{+}}\left(B i_{n}^{q+}\right)=\frac{Y_{B i_{n}^{q+}} I_{B i_{n}^{q+}}}{Y_{B i} I_{B i_{1}^{+}}}
$$

For the present work, $R_{B i_{1}^{+}}\left(B i_{n}^{q+}\right)$ is calculated relatively to $\mathrm{Bi}_{1}^{+}$. The higher the value the better the primary ion species $\mathrm{Bi}_{n}^{q+}$ is suited for imaging.

6. Useful lateral resolution $\Delta L$ is the side of the minimum square area in which $N$ secondary ions of a given mass can be desorbed and detected. This corresponds to the area $\Delta L^{2}$, which has to be damaged to record $N$ secondary ions. For $N=4$ one obtains $\Delta L=(4 / E)^{1 / 2}$. The $\Delta L$ is related to the secondary ion emission. It is obviously sample dependent and generally is not equal to the lateral resolution, which, to the contrary, depends on the beam spot size. 


\section{Sample Preparation}

A rat brain was cut at a temperature of $-18{ }^{\circ} \mathrm{C}$ in a cryostat (model CM3050-S; Leica Microsystèmes SA, Rueil-Malmaison, France). The tissue sections, which have a thickness of $15 \mu \mathrm{m}$, were immediately deposited onto a stainless steel plate and kept at $-80{ }^{\circ} \mathrm{C}$. Just before analysis the plates were warmed to room temperature and dried under a pressure of a few millibars for $\sim 1 \mathrm{~h}$. No treatment was applied on the samples that were neither rinsed nor matrix coated. The stainless steel plates, purchased from Goodfellow (Ermine Business Park, Huntingdon, England), were laminated and the composition was (15-7PH) $\mathrm{Fe}, 75 \%$; $\mathrm{Cr} 15 \%, \mathrm{Ni}, 7 \%$; and Mo, 2.25\% (weight \%).

\section{Results and Discussion}

Tissue Sections: Yields, Disappearance Cross Sections, Efficiencies, Relative Imaging Efficiencies, and Useful Lateral Resolution

The disappearance cross sections were determined by bombarding an area of $100 \times 100 \mu \mathrm{m}^{2}$ of the surface of the rat brain tissue sections and monitoring the secondary ion intensity as a function of time (decay curve). From the slope of the decay curve $\ln (I)$ versus time, $\sigma$ can be calculated. For the yield determination, spectra were extracted from the beginning of the irradiation (intercept of the decay curve versus time). Peak integral values were determined and yields were calculated by dividing the peak integral values by the primary ion dose. The corresponding efficiency $E$ was determined by dividing the obtained yields by the corresponding disappearance cross sections. For each primary ion species data were taken from two freshly selected positions. It is known that the intensity of secondary ions can differ between the regions of the brain section

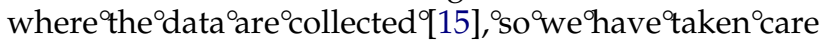
to always record the data from inside the corpus callosum. The values have been measured on the rat brain tissue sections for different positive and negative secondary ${ }^{\circ}$ ions. ${ }^{\circ}{ }^{\circ}$ The ${ }^{\circ}$ results ${ }^{\circ}$ are ${ }^{\circ}$ summarized ${ }^{\circ}{ }^{\circ}{ }^{\circ}$ Table $^{\circ} 1$ and Figure $2{ }^{\circ}$ for $\left.{ }^{\circ} \mathrm{M}^{\circ}-\mathrm{H}\right]^{+}{ }^{\circ}$ secondary ${ }^{\circ}$ ions ${ }^{\circ}$ of ${ }^{\circ}$ cholesterol $(\mathrm{m} / \mathrm{z} 385)$, showing the average values over the two positions (other data not shown). The data could not be exactly compared with those obtained in the paper of

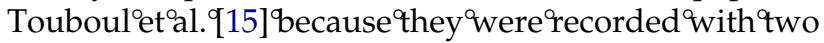

slightly different mass spectrometers and from different tissue sections (from a mouse brain in the mentioned reference and from a rat brain in the present work). Nevertheless, estimated values for $\mathrm{Au}_{1}^{+}$and $\mathrm{Au}_{3}^{+}$have been $^{\circ}$ added $^{\circ}$ in $^{\circ}$ Figure $^{\circ} 2{ }^{\circ}{ }^{\circ}$ assuming ${ }^{\circ}$ that $^{\circ}$ yields ${ }^{\circ} Y$ and disappearance cross sections $\sigma$ must be equal for $\mathrm{Au}_{1}^{+}$ and $\mathrm{Bi}_{1}^{+}$and for $\mathrm{Au}_{3}^{+}$and $\mathrm{Bi}_{3}^{+}$, respectively. This extrapolation is valid because gold is an element located nearby bismuth in the periodic table (atomic numbers 79 and 83, respectively). It is known that the nuclear stopping is mainly responsible for the organic secondary ion production in the present impact energy range [25]..$^{\circ}$ When ${ }^{\circ}$ comparing $^{\circ}$ with ${ }^{\circ}$ the ${ }^{\circ}$ SRIM $^{\circ}$ (stopping ${ }^{\circ}$ and ranges $^{\circ}$ of $^{\circ}$ ions $^{\circ}$ in $^{\circ}$ matter $)^{\circ}$ code $^{\circ}[26]^{\circ}$, the $^{\circ}$ nuclear stopping of gold and bismuth into adipose tissue (brain tissue is not available with SRIM), it is found that the difference is never greater than $2 \%$ between 5 and 50 $\mathrm{keV}$.

It ${ }^{\circ}$ as ${ }^{\circ}$ been ${ }^{\circ}$ shown ${ }^{\circ} y^{\circ}{ }^{\circ}$ enguerba ${ }^{\circ}{ }^{\circ}{ }^{\circ} a l .{ }^{\circ}[14]^{\circ}$ and ${ }^{\circ}$ more

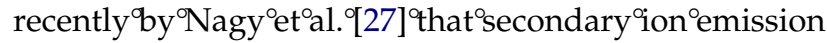
yields under the impact of $\mathrm{Au}_{n}^{+}$clusters were proportional to $n^{2} v^{2}$, with $n$ and $v$ being the number of constituents and the velocity of the projectiles, respectively. The following discussion is supported by this important feature. In the present work, the singly charged projectiles $\mathrm{Bi}_{1}^{+}, \mathrm{Bi}_{3}^{+}, \mathrm{Bi}_{5}^{+}$, and $\mathrm{Bi}_{7}^{+}$have a kinetic energy of $25 \mathrm{keV}$, and the doubly charged species $\mathrm{Bi}_{3}^{2+}$ and $\mathrm{Bi}_{5}^{2+}$ have twice the value, that is, $50 \mathrm{keV}$. The secondary ion emission induced by these different projectiles can be compared, keeping in mind that at the same kinetic energy, the velocities range inversely to the square root of the number of constituents. Singly and doubly charged species having the same number of constituents enable us to study the influence of the velocity independently of the projectile mass.

The yield increases by a factor of 8.4 when switching from $\mathrm{Bi}_{1}^{+}$to $\mathrm{Bi}_{3}^{+}$whereas the disappearance cross section only rises by a factor of 1.6 resulting in an efficiency enhancement by a factor of 5 . Therefore, the secondary ion generation is more efficient with $\mathrm{Bi}_{3}^{+}$bombardment than with $\mathrm{Bi}_{1}^{+}$bombardment and a lower primary ion can be used.

Yields and efficiencies for $\mathrm{Bi}_{3}^{2+}$ are unexpectedly very similar to those obtained for $\mathrm{Bi}_{3}^{+}$, although its kinetic energy is $50 \mathrm{keV}$ instead of $25 \mathrm{keV}$. It can be seen in Ref. $[28]^{\circ}$ that ${ }^{\circ}$ the ${ }^{\circ}$ energy ${ }^{\circ}$ per $^{\circ}$ atom $^{\circ}$ for $^{\circ}$ which ${ }^{\circ}$ the ${ }^{\circ}$ secondary ion emission yield maximum occurs was not measured

Table 1. Secondary ion yields $Y$, disappearance cross section $\sigma$, ion bombardment efficiencies $E$, relative specific data rate $R_{\mathrm{Bi}_{1}^{+}}$and useful lateral resolution $\Delta L$ for $\mathrm{Bi}_{\mathrm{n}}{ }^{\mathrm{q}^{+}}$bombardment of cholesterol $\left([\mathrm{M}-\mathrm{H}]^{+} ; m / z 385\right)$ in the corpus callosum of a rat brain section.

\begin{tabular}{lcccrr}
\hline Primary ion & $Y$ & $\sigma\left(\mathrm{cm}^{2}\right)$ & $E\left(\mathrm{~cm}^{-2}\right)$ & $R_{\mathrm{Bi}_{+}^{+}}$ & $\Delta L(\mathrm{~nm})$ \\
\hline \hline $\mathrm{Bi}_{1}^{+}$ & $8.36 \times 10^{-05}$ & $2.75 \times 10^{-13}$ & $3.04 \times 10^{+08}$ & 1.00 & 1148 \\
$\mathrm{Bi}_{3}^{+}$ & $7.06 \times 10^{-04}$ & $4.14 \times 10^{-13}$ & $1.71 \times 10^{+09}$ & 2.86 & 484 \\
$\mathrm{Bi}_{3}^{2+}$ & $6.39 \times 10^{-04}$ & $4.96 \times 10^{-13}$ & $1.29 \times 10^{+09}$ & 1.41 & 557 \\
$\mathrm{Bi}_{5}^{+}$ & $3.16 \times 10^{-04}$ & $4.43 \times 10^{-13}$ & $7.14 \times 10^{+08}$ & 0.17 & 749 \\
$\mathrm{Bi}_{5}^{2+}$ & $9.91 \times 10^{-04}$ & $3.52 \times 10^{-13}$ & $2.81 \times 10^{+09}$ & 0.52 & 377 \\
$\mathrm{Bi}_{7}^{+}$ & $4.06 \times 10^{-04}$ & $1.92 \times 10^{-12}$ & $2.12 \times 10^{+08}$ & $1.94 \times 10^{-2}$ & 1374 \\
\hline
\end{tabular}


(a)

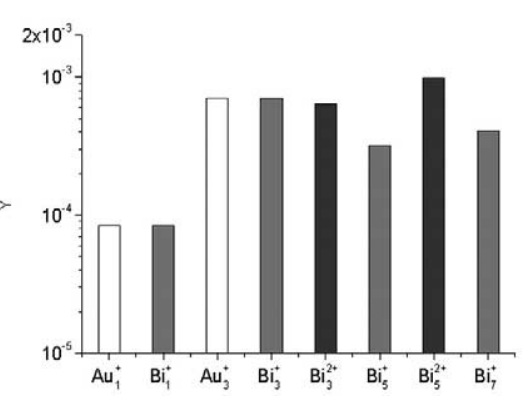

(b)

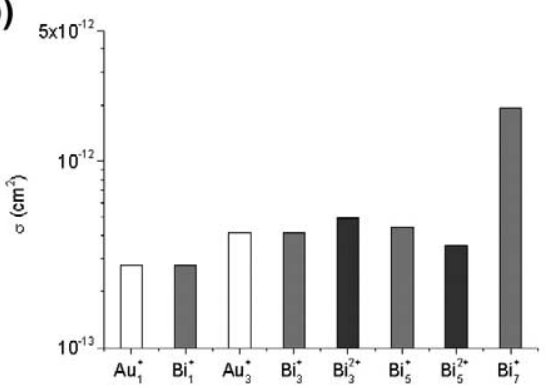

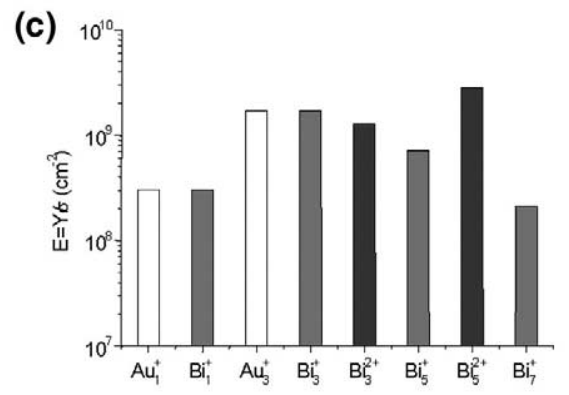

(d)

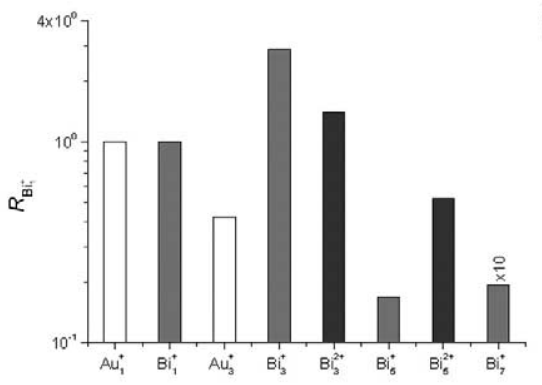

(e)

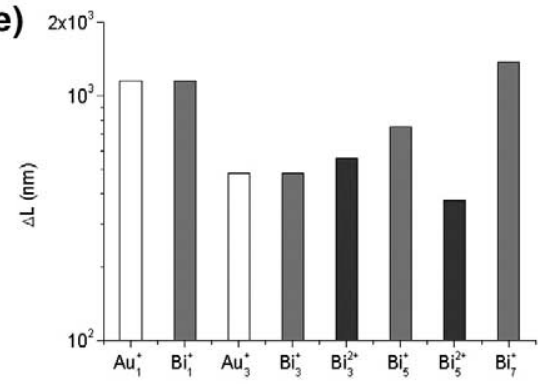

Figure 2. (a) Secondary ion yields $Y$; (b) disappearance cross sections $\sigma$; (c) efficiencies $E$; (d) relative specific data rate; $R_{B i^{+}}$, (e) useful lateral resolutions $\Delta L$, all measured for the $[\mathrm{M}-\mathrm{H}]^{+}$ions of cholesterol in the corpus callosum of a rat brain tissue section and under $\mathrm{Bi}_{n}^{q+}$ primary ion bombardment. Gray bars are for singly charged ions; black bars are for doubly charged ions. Estimated values for Au clusters are shown with white bars for comparison.

with precision (see, e.g., the results with the phenylalanine and lipid ethylene glycol compounds, where it is clearly written that the solid curves were only to guide the eye). Without further experimental results, the energy value of the maximum can range between $\sim 10-15$ and $\sim 40-80 \mathrm{keV}$ per atom, likely depending on both the size of the projectile and the irradiated compound. Therefore, a possible explanation of the similar yields for $\mathrm{Bi}_{3}^{+}$and $\mathrm{Bi}_{3}^{2+}$ could be that the velocity of a $50-\mathrm{keV}$ energy $\mathrm{Bi}_{3}^{2+}$ is too high with respect to the secondary ion emission maximum.

$\mathrm{Bi}_{5}^{+}$produces lower yield and efficiency values than $\mathrm{Bi}_{3}^{+}$. This is probably because the expected increase of yield due to the increase of projectile mass is in this case counterbalanced by the decrease of velocity at the same total kinetic energy.

On the other hand, the yield obtained with $\mathrm{Bi}_{5}^{2+}$ ions is higher than for $\mathrm{Bi}_{3}^{+}$and the disappearance cross section is lower, leading to an efficiency of about 1.6 times greater than for $\mathrm{Bi}_{3}^{+}$. In this case, the increase of mass is not counterbalanced by a decrease of velocity, because $\mathrm{Bi}_{5}^{2+}$ has a velocity that is slightly higher than the one of $\mathrm{Bi}_{3}^{+}$.

The $\mathrm{Bi}_{7}^{+}$projectiles have a surprisingly low efficiency, which is only the same as for $\mathrm{Bi}_{1}^{+}$. Because the primary ion current is very low, the corresponding measurement time to achieve a sufficient primary ion dose density is rather long. In this case the sample damage caused by the low-energy electron beam used to compensate sample charging can no longer be neglected ${ }^{\circ}[29]$.

Therefore, $\mathrm{Bi}_{5}^{2+}$ ions are the best projectiles for spectroscopy measurements. This also can be illustrated by looking at the useful lateral resolutions, which are the best $(377 \mathrm{~nm})$ for $\mathrm{Bi}_{5}^{2+}$, whereas it is $\sim 500 \mathrm{~nm}$ for $\mathrm{Bi}_{3}^{+}$ and more than $1 \mu \mathrm{m}$ for $\mathrm{Bi}_{1}^{+}$.

To compare the imaging capabilities of these primary ions, it is necessary to take into account the primary ion currents in addition to the aforementioned results. Indeed, a primary ion that would have the best efficiency but the smallest intensity would not be able to acquire secondary ion images in a short time. The 
Field of view: $18000.0 \times 18000.0 \mu m^{2}$

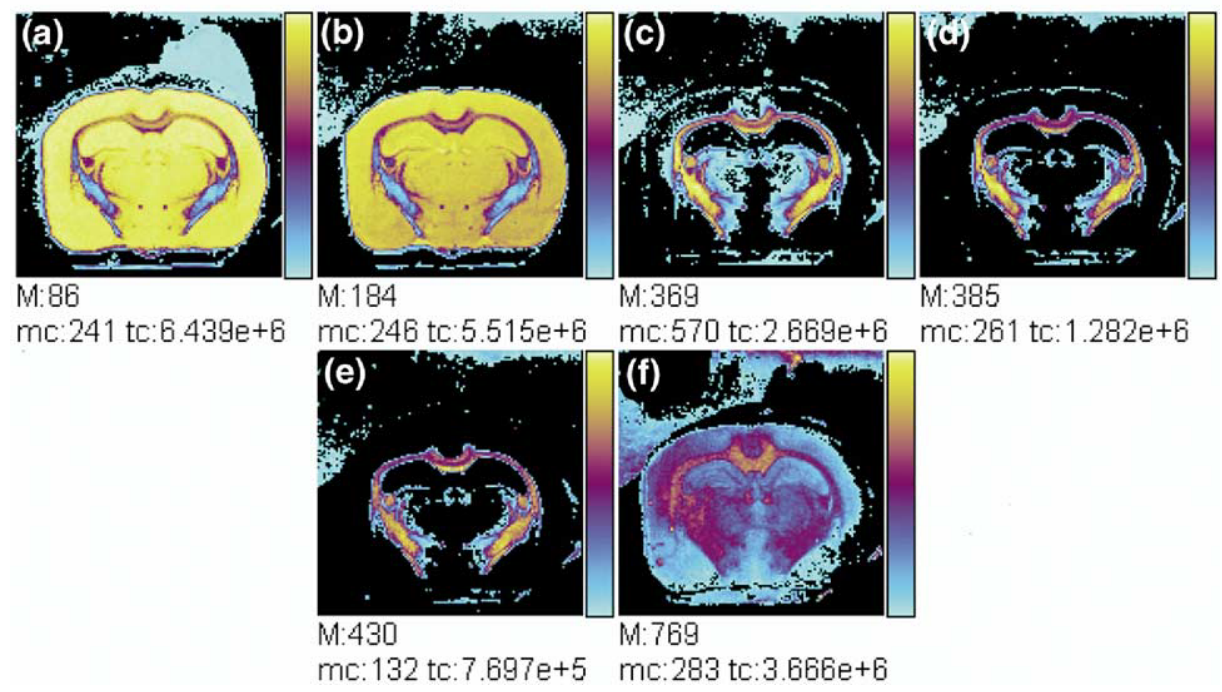

Figure 3. Positive secondary ion images obtained from a rat brain section under the irradiation of $\mathrm{Bi}_{3}^{+}$ primary ions. $256 \times 256$ pixels, pixel size $70 \times 70 \mu \mathrm{m}^{2}$. See text for details.

influence of the low-energy electron damage makes it even more important to achieve short measurement times. That is the reason why we have introduced the additional parameter $R$. This parameter takes into account both the secondary ion emission yield and the primary $90^{\circ}$ current. Figure $2 d^{\circ}$ shows that ${ }^{\circ}$ for large-area imaging purposes it is $\mathrm{Bi}_{3}^{+}$that is the best primary ion, having the highest value of $R$. Because the $\mathrm{Bi}_{3}^{+}$ion intensity is about seven times higher than it was for $\mathrm{Au}_{3}^{+}$, a secondary ion image can be recorded with the same signal intensity within a seven times shorter acquisition time, or during equivalent acquisition times one may record an image with a seven times signal intensity. This is particularly important when recording secondary ion images of large areas such as for an entire rat brain section (more than $3 \mathrm{~cm}^{2}$ ), for which it takes a long time to reach a primary ion dose density higher than a few $10^{9}$ ions $\cdot \mathrm{cm}^{-2}$. Otherwise, if only areas smaller than $500 \times 500 \mu \mathrm{m}^{2}$ are considered, the limited sample material becomes significant. In this case $\mathrm{Bi}_{5}^{2+}$ ions are preferable because of their particularly attractive efficiency.

A tissue section is obviously not a homogeneous surface and is consequently not best suited to precisely measure the foregoing values, which can change significantly from one irradiated area to another. In addition, the ${ }^{\circ}$ values $^{\circ}$ presented ${ }^{\circ}$ in $^{\circ}$ Table $^{\circ} 1^{\circ}$ and ${ }^{\circ}$ Figure $^{\circ} 2,{ }^{\circ}$ particularly the useful lateral resolution, are significant only

Field of view: $18000.0 \times 18000.0 \mu m^{2}$
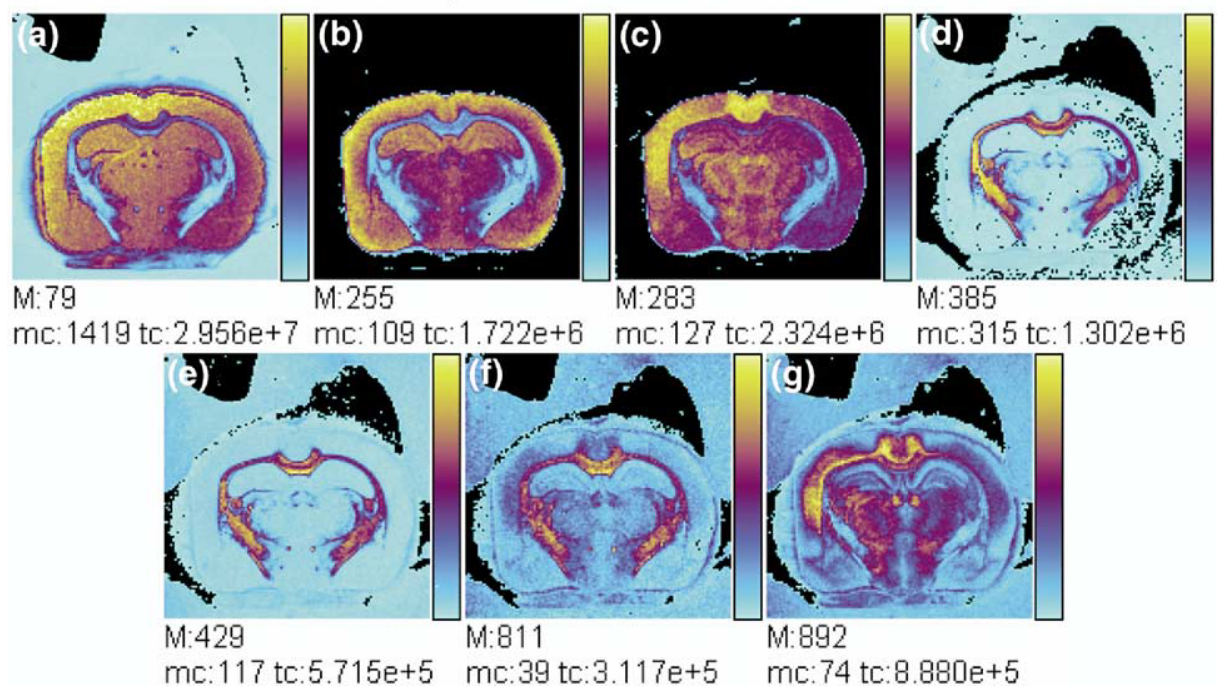

Figure 4. Negative secondary ion images obtained from a rat brain section under the irradiation of $\mathrm{Bi}_{3}^{+}$primary ions. $256 \times 256$ pixels, pixel size $70 \times 70 \mu \mathrm{m}^{2}$. See text for details. This image has been

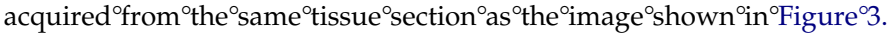




\section{Field of view: $18000.0 \times 18000.0 \mu \mathrm{m}^{2}$}

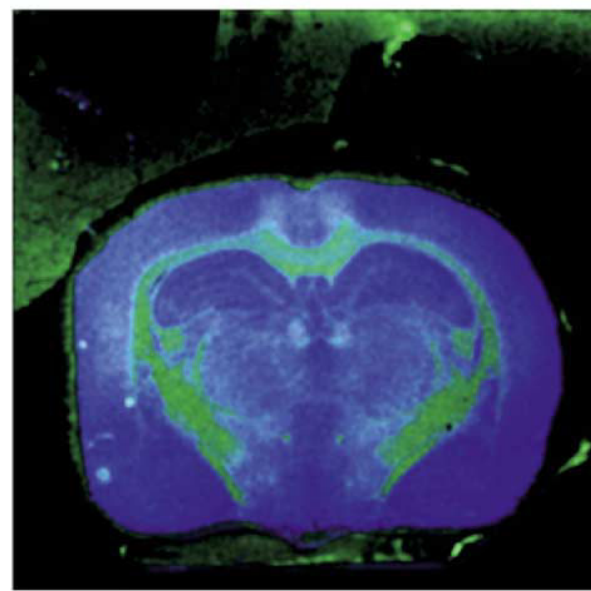

Blue=184

Green $=769$

Figure 5. Color overlay showing the different localizations of the positive ions at $\mathrm{m} / \mathrm{z} 184$ (blue) and $\mathrm{m} / \mathrm{z} 769$ (green). Same data acquisition ${ }^{\circ}$ as $^{\circ}$ for $^{\circ}$ Figure $^{\circ} 3$.

for the present model, which is a rat brain section. Nevertheless, the conclusions concerning the two most relevant primary ions $\mathrm{Bi}_{3}^{+}$and $\mathrm{Bi}_{5}^{2+}$ can be extrapolated to other biological or even nonbiological models.

\section{Tissue Sections: Imaging}

The area of the square circumscribed by the section is 18 $\times 18 \mathrm{~mm}^{2}$. The corresponding images $(256 \times 256$ pixels $)$ are obtained within $3.5 \mathrm{~h}$ with a spatial resolution of 70 $\mu \mathrm{m}, 256$ shots per pixel, and a primary ion dose density of $10^{9} \mathrm{Bi}_{3}^{+}$ions $^{\circ} .^{\circ} \mathrm{cm}^{-2}$. ${ }^{\circ}$ Figure $^{\circ} 3 \mathrm{a},{ }^{\circ} \mathrm{f}^{\circ}$ displays ${ }^{\circ}$ images corresponding to the positive fragment ions of choline $(\mathrm{m} / \mathrm{z}$ 86), phosphocholine head group $(\mathrm{m} / \mathrm{z} 184)$, cholesterol $\left[\mathrm{M}+\mathrm{H}-\mathrm{H}_{2} 0\right]^{+}(m / z 369)$ and $[\mathrm{M}-\mathrm{H}]^{+}(m / z 385)$,
Vitamin E ( $m / z$ 430), and phospholipids (mean $m / z$ 769), respectively. Different zones are precisely identified with an anatomic atlas $[30]$. The ${ }^{\circ}$ presence ${ }^{\circ}$ s. $^{\circ}$ such $^{\circ}{ }^{\circ}{ }^{\circ}{ }^{\circ}$ at the surface of a rat brain section has already been described ${ }^{\circ}{ }^{\circ}{ }^{\circ}$ discussed $^{\circ}$ in the literature $^{9}[15,16]$. ${ }^{\circ}$. Figure $4 \mathrm{a},{ }^{\circ} \mathrm{g}^{\circ}$ shows $^{\circ}$ images $^{\circ}$ of $^{\circ}$ negative ${ }^{\circ}$ ions, ${ }^{\circ}$ which ${ }^{\circ}$ were acquired after the acquisition of the positive ion images, exactly on the same area of the same rat brain section. The image shows the spatial distributions of phosphate ions $\left[\mathrm{PO}_{3}\right]^{-}(\mathrm{m} / \mathrm{z} 79)$, carboxylate ions of C16:0 $(\mathrm{m} / \mathrm{z} 255)$ and C18:0 $(\mathrm{m} / \mathrm{z} 283)$ fatty acids, cholesterol $[\mathrm{M}-\mathrm{H}]^{-}$ ions $(\mathrm{m} / \mathrm{z} 385)$, vitamin $\mathrm{E}$ ions $(\mathrm{m} / \mathrm{z} 429)$, and triglyceride ions $(\mathrm{m} / \mathrm{z} 811$ and 892$)$. The intensity scales of these images are much higher than could be previously obtained with $\mathrm{Au}_{3}^{+}$gold clusters and equivalent acquisition times. The increase of primary ion intensity with the bismuth LMIG makes it possible to acquire such large-area images in only a few hours, with a primary ion dose density leading to very good image contrast (scales of several tens or more) of secondary ions heavier than $500 \mathrm{Da}$, such as phospholipids or triglycerides. These images show with precision some particular structures of the brain, such as the inner structure of $^{\circ}$ the ${ }^{\circ}$ gyrus $^{\circ}$ dente $^{\circ}$ (Figure $\left.{ }^{\circ} 4 \mathrm{~g}\right)$.

One can observe from the positive ion images that the ions at $\mathrm{m} / \mathrm{z} 184$ are not only coming from the fragmentation of glycerophosphatidycholine ions, but also can come from phosphocholine itself, because the distribution of the ions at $\mathrm{m} / \mathrm{z} 184$ and 769 (average value) are different. This also is illustrated with the color ${ }^{\circ}$ overlay ${ }^{\circ}$ shown ${ }^{\circ}{ }^{\circ}{ }^{\circ}$ Figure ${ }^{\circ} 5 .{ }^{\circ} \mathrm{A}^{\circ}$ substructure ${ }^{\circ}$ inside the corpus callosum also can be observed from both the positive and the negative ion images. An inner line corresponds to a colocalization of C18 fatty acids-and not C16 ones-with triglycerides and phosphocholine. In the same inner line, other ions such as cholesterol and ${ }^{\circ}$ vitamin $^{\circ} \mathrm{E}^{\circ}$ (Figures ${ }^{\circ} \mathrm{c}^{\circ},{ }^{\circ} \mathrm{d}^{\circ}$ and $\left.^{\circ} 4 \mathrm{~d}\right)^{\circ}$ are ${ }^{\circ}$ less ${ }^{\circ}$ abundant while mainly present in the corpus callosum. An area at

\section{Field of view: $18000.0 \times 18000.0 \mu m^{2}$}

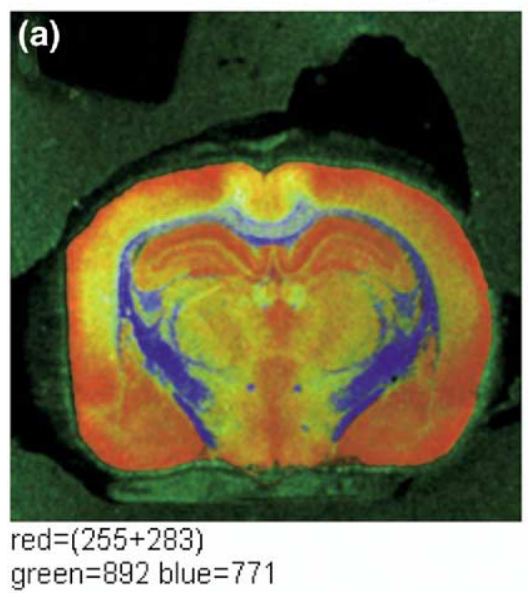

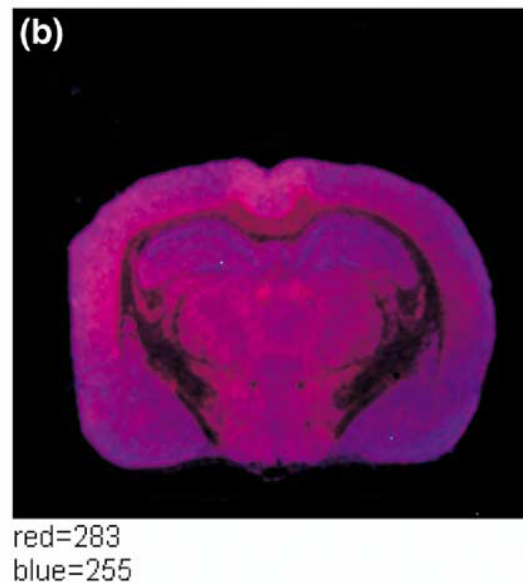

blue $=255$

Figure 6. Color overlays showing the different localizations of the following negative ions: (a) $\mathrm{m} / \mathrm{z}$ $(255$ + 283; red), $m / z 892$ (green), and $m / z 771$ (blue); (b) $m / z 255$ (blue) and $m / z 283$ (red). Same data acquisition $^{\circ}$ as $^{\circ}$ for $^{\circ}$ Figure $^{\circ} 4$. 
Field of view: $256.0 \times 256.0 \mu^{2}$

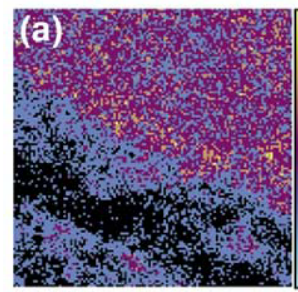

M:184

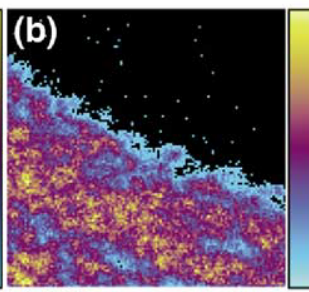

M:369

mc: 16 tc: $1.924 \mathrm{e}+5$

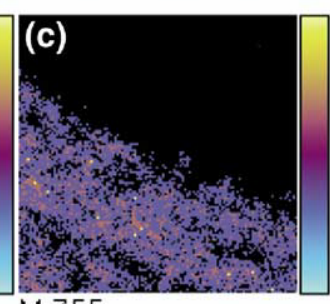

M:755

mc: 7 tc: $4.690 \mathrm{e}+4$ mc:8 tc: $1.099 \mathrm{e}+5$

Field of view. $255.9 \times 255.9 \mu^{2}$

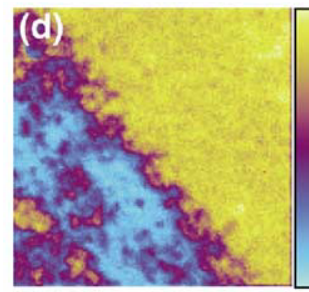

M:184

M:369

Field of view: $256.0 \times 256.0 \mu^{2}$

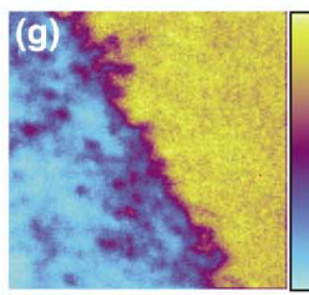

M:184

mc:91 tc: $2.654 \mathrm{e}+6$

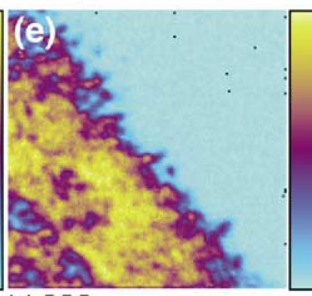

mc: 118 tc: $2.366 \mathrm{e}+6$

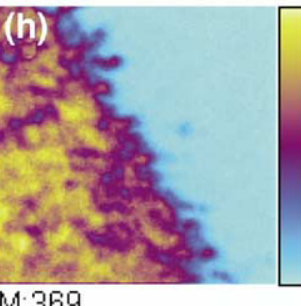

M:369

mc: 190 tc: $4.205 \mathrm{e}+6$

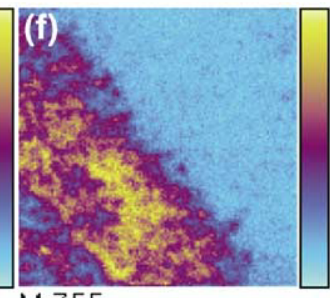

M:755

mc: 45 tc: $7.969 \mathrm{e}+5$

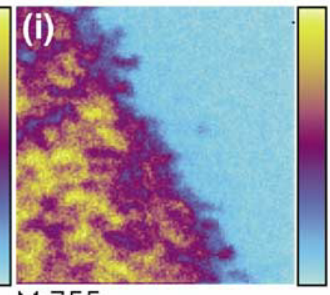

M:755

$m c: 61$ tc: $1.168 \mathrm{e}+6$

\section{$\mathrm{Bi}_{1}^{+}$}

\section{$\mathrm{Bi}_{3}{ }^{+}$}

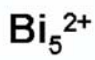

Figure 7. Positive secondary ion images obtained under the irradiation of $\mathrm{Bi}_{1}^{+}, \mathrm{Bi}_{3}^{+}$and $\mathrm{Bi}_{5}^{2+}$ primary ions and with the same primary ion dose density of $10^{12}$ ions $\cdot \mathrm{cm}^{-2}$. The corpus callosum is on the left part of the images $\left(256 \times 256\right.$ pixels, pixel size $\left.1 \times 1 \mu \mathrm{m}^{2}\right)$. the top center of the brain shows a particular abundance of ${ }^{\text {triglyceride }}$ ions $^{\text {(Figure }} 4 \mathrm{~g}$ ), ' which here are localized with ${ }^{\circ}$ the ${ }^{\circ} \mathrm{C} 18^{\circ}$ fatt ${ }^{\circ}{ }^{\circ}$ cid $^{\circ}$ ions ${ }^{\circ}$ (Figure ${ }^{\circ} 4 \mathrm{c}$ ), , indicating $^{\circ}$ that in this region these fatty acid are mainly coming from fragmentation of the triglycerides. The localization of fatty ${ }^{\circ} a^{\circ} i d s^{\circ} a^{\circ}{ }^{\circ}$ triglycerides ${ }^{\circ}$ also ${ }^{\circ}$ is $^{\circ}$ illustrated ${ }^{\circ}{ }^{\circ}{ }^{\circ}$ Figure $6 a,{ }^{\circ}$ and $^{\circ}$ the ${ }^{\circ}$ Figure $^{\circ} 6 \mathrm{~b}^{\circ}$ clearly $^{\circ}$ shows ${ }^{\circ}$ the ${ }^{\circ}$ differences ${ }^{\circ}$ in the spatial distribution of $\mathrm{C} 16$ and $\mathrm{C} 18$ fatty acids. A small intensity difference between the left and the right

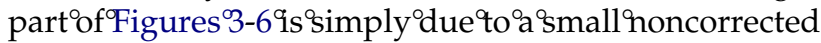
height difference of the sample that slightly changed the secondary ion extraction conditions. An interpolation method has been used for a few pixels to correct for a temporary loss of signal.

To compare the capabilities of the different bismuth cluster beams for small-area imaging, the following data acquisitions were made from areas of $256 \times 256$ $\mu \mathrm{m}^{2}\left(256 \times 256\right.$ pixels, pixel size $\left.1 \times 1 \mu \mathrm{m}^{2}\right)$, always with the same primary ion dose density of $10^{12}$ ions . $\mathrm{cm}^{-2}$. The images were all acquired at the edge of the corpus callosum, each one on a different area to always ensure a fresh and nonirradiated zone. The primary ions chosen for the comparison were $\mathrm{Bi}_{1}^{+}, \mathrm{Bi}_{3}^{+}$, and $\mathrm{Bi}_{5}^{2+}$.
With regard to the available pulsed primary ion intensities, the time necessary to reach $10^{12}$ ions $\cdot \mathrm{cm}^{-2}$ was, respectively, less than 4 min for $\mathrm{Bi}_{1}^{+}, 10.5 \mathrm{~min}$ for $\mathrm{Bi}_{3}^{+}$, and $100 \mathrm{~min}$ for $\mathrm{Bi}_{5}^{2+} .{ }^{\circ}$ Figure ${ }^{\circ} 7^{\circ}$ shows ${ }^{\circ}$ the ${ }^{\circ}$ resulting images for three different positive ions $(\mathrm{m} / \mathrm{z} 184,369$, and $755^{\circ}$ average value) and Figure 8 shows the resulting images for two different negative ions $(\mathrm{m} / \mathrm{z} 385$ and 771 average value). Clearly, $\mathrm{Bi}_{1}^{+}$can be considered sufficiently efficient to acquire an image of light positive ions such as those of the phosphocholine head group $\left(\mathrm{m} / \mathrm{z} 184 \text {, }{ }^{\circ} \text { Figure } \% \mathrm{a}\right)^{\circ}$ and ${ }^{\circ}$ cholesterol ${ }^{\circ}\left[\mathrm{M}^{\circ}+{ }^{\circ} \mathrm{H}^{\circ}-{ }^{\circ} \mathrm{H}_{2} \mathrm{O}\right]^{+}$at $\mathrm{m} / \mathrm{z} 369^{\circ}$ (Figure $\mathrm{Cb}$ ) ${ }^{\circ}$ or $^{\circ}$ other $^{\circ}{ }^{\circ} \mathrm{ions}^{\circ}$ (data ${ }^{\circ}$ not $^{\circ}$ shown) ${ }^{\circ}$ such as sodium $(\mathrm{m} / \mathrm{z} 23)$, potassium $(\mathrm{m} / \mathrm{z} 39)$, and phosphocholine fragment $(\mathrm{m} / \mathrm{z}$ 86). Nevertheless, images of heavier mass-to-charge ratio ions such as phospholipids $\left(\text { mean }^{\circ} \mathrm{m} / \mathrm{z} 755 \text {, }^{\circ} \text { Figure }^{\circ} \mathrm{c}\right)^{\circ}{ }^{\circ}$ are $^{\text {obarely }}{ }^{\circ}$ distinguished ${ }^{\circ}$ with $\mathrm{Bi}_{1}^{+}$primary ions. $\mathrm{Bi}_{3}^{+}$provides much more contrasted images ${ }^{\circ}$ for ${ }^{\circ}$ all these positive $^{\circ}$ secondary ${ }^{\circ}{ }^{\circ}{ }^{\circ}{ }^{\circ}$ (Figures $\% \mathrm{~d}$, $\mathrm{f})$, and the intensities are further increased when using $\mathrm{Bi}_{5}^{2+}$ (Figures $\left.^{\circ} 7 \mathrm{~g}-\mathrm{i}\right) .^{\circ}$ The $^{\circ}$ same $^{\circ}$ observations ${ }^{\circ}$ are ${ }^{\circ}$ reinforced in the negative ion mode, where only the secondary ions corresponding to cholesterol $[\mathrm{M}-\mathrm{H}]^{-}$ $\left(m / z 385,{ }^{\circ}\right.$ Figure ${ }^{\circ} \mathrm{a}$ ) ${ }^{\circ}$ and $^{\circ}$ vitamin $^{\circ} \mathrm{E}^{\circ}\left(\right.$ not $^{\circ}$ shown, $^{\circ} \mathrm{m} / z$ 429) 
Field of view: $256.0 \times 256.0 \mu \mathrm{m}^{2}$
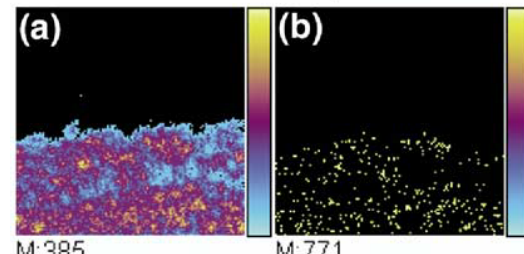

M:385

M:771

mc: 14 tc: $1.338 \mathrm{e}+5 \quad m c: 4$ tc: $1.483 \mathrm{e}+4$

Field of view: $256.0 \times 256.0 \mu \mathrm{m}^{2}$

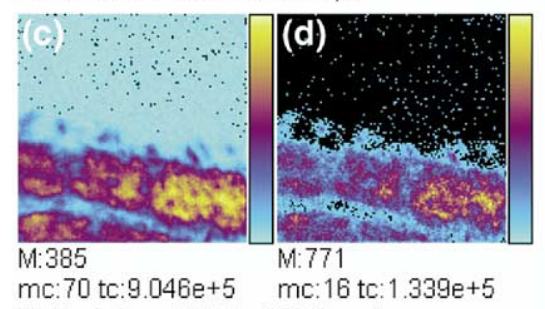

Field of view: $256.0 \times 256.0 \mu \mathrm{m}^{2}$

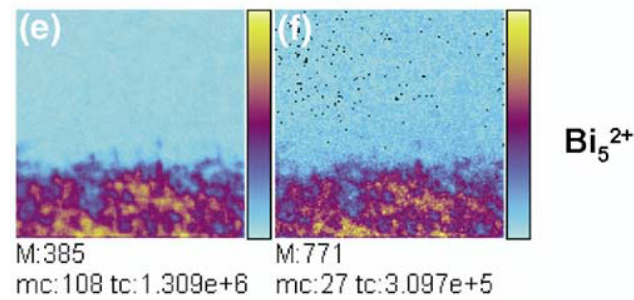

Figure 8. Negative secondary ion images obtained under the irradiation of $\mathrm{Bi}_{1}^{+}, \mathrm{Bi}_{3}^{+}$, and $\mathrm{Bi}_{5}^{2+}$ primary ions and with the same primary ion dose density of $10^{12}$ ions $\cdot \mathrm{cm}^{-2}$. The corpus callosum is on the bottom part of the images $(256 \times 256$ pixels, pixel size 1 $\left.\times 1 \mu \mathrm{m}^{2}\right)$.

can be distinguished when using $\mathrm{Bi}_{1}^{+}$primary ions. The images corresponding to other ions such as the carboxylate ions of C16:0 (m/z 255) and C18:0 (m/z 283) fatty acids or triglycerides (not shown) show little contrast and the images corresponding to the other negative ions such ${ }^{\circ}{ }^{\circ} \mathrm{m} / \mathrm{z} 771^{\circ}$ (Figure $8 \mathrm{~b}$ ) ${ }^{\circ}$ are ${ }^{\circ}$ completely black. On the contrary, the use of $\mathrm{Bi}_{3}^{+}$(Figure ${ }^{\circ} \mathrm{c}, \stackrel{\circ}{\circ}$ ) and, 'furthermore, the use of $\mathrm{Bi}_{5}^{2+}$, largely increases the intensities, making all $^{\circ}$ the ${ }^{\circ}$ images $^{\circ}$ easily $^{\circ}$ observable $^{\circ}\left(\right.$ Figure $\left.^{\circ} 8 \mathrm{e},{ }^{\circ} \mathrm{f}\right) .^{\circ}$ At ${ }^{\circ}$ this step of the discussion, one should remember that the useful lateral resolution measured with cholesterol ions is $\sim 500 \mathrm{~nm}$ for $\mathrm{Bi}_{3}^{+}$and less than $400 \mathrm{~nm}$ for $\mathrm{Bi}_{5}^{2+}$. Indeed, apparently the accuracy of the images obtained with $\mathrm{Bi}_{5}^{2+}$ is better than with $\mathrm{Bi}_{3}^{+}$, although both recorded with the same pixel size (the pixel size, the useful lateral resolution, and the beam size have the same order of magnitude; therefore, the accuracy depends on these three parameters). For all the secondary ions shown the number of counts is better with $\mathrm{Bi}_{5}^{2+}$ than with $\mathrm{Bi}_{3}^{+}$. When switching from $\mathrm{Bi}_{1}^{+}$to $\mathrm{Bi}_{3}^{+}$primary ion beams, the increase of counts and contrast is obtained at the expense of an acquisition time lengthened by a factor 2.6 (from 4 to $10.5 \mathrm{~min}$ ). In the meantime, the acquisition time is further increased tenfold when changing the $\mathrm{Bi}_{3}^{+}$to $\mathrm{Bi}_{5}^{2+}$ ions. This drawback is counterbalanced by the enormous advantage of having the best efficiency and the best useful lateral resolution. It
Field of view: $256.0 \times 256.0 \mu \mathrm{m}^{2}$

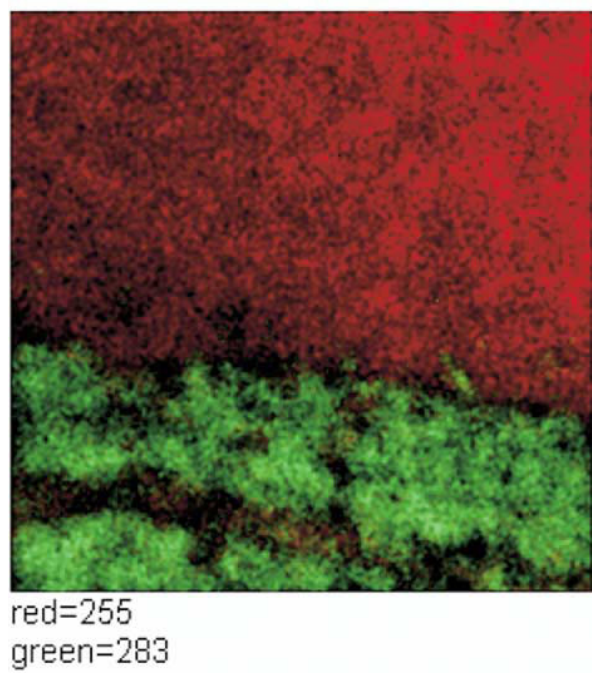

Figure 9. Two-color overlay showing the different localizations of the negative ions at $\mathrm{m} / \mathrm{z} 255$ (red) and $\mathrm{m} / \mathrm{z} 283$ (green). The corpus callosum is at the bottom part of the image. Same data acquisition ${ }^{\circ}{ }^{\circ}$ for ${ }^{\circ}$ Figure $8 \mathrm{c}-\mathrm{c} \mathrm{d}^{\circ}\left(\mathrm{Bi}_{3}^{+}\right.$primary ions, $256 \times 256$ pixels, pixel size $1 \times 1 \mu \mathrm{m}^{2}$ ).

makes it possible to successfully image, for example, very thin areas at the edge of the corpus callosum, corresponding to only a few cells and having a thickness of less than $50 \mu \mathrm{m}$ (see, e.g., ions at $\mathrm{m} / \mathrm{z} 385$ in Figure $\left.^{\circ} 8 \mathrm{e}\right) .{ }^{\circ}$ Edgings $^{\circ}$ between $^{\circ}$ different $^{\circ}$ regions ${ }^{\circ}$ also ${ }^{\circ}$ can

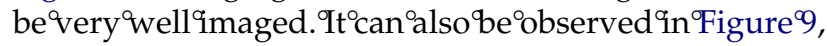
as in Figure 4 , that ${ }^{\circ}$ carboxylate ions ${ }^{\circ}{ }^{\circ} \mathrm{C} 16^{\circ}$ and ${ }^{\circ} \mathrm{C} 18{ }^{\circ}$ fatty acids have different localizations (negative one to the other in this region) at the edge of the corpus callosum. Finally, ${ }^{\circ}$ Figure ${ }^{\circ} 10^{\circ}$ shows $^{\circ}$ that ${ }^{\circ} i^{\circ}{ }^{\circ}$ is ${ }^{\circ}$ possible ${ }^{\circ}$ to $^{\circ}$ obtain ${ }^{\circ}$ the image of ions heavier than $1000 \mathrm{Da}$ with a pixel size of only $1 \times 1 \mu \mathrm{m}^{2}$ when using $\mathrm{Bi}_{5}^{2+}$ as primary ions. On the other ${ }^{\circ}$ hand, ${ }^{\circ}$ Figure $^{\circ} 11^{\circ}$ shows $^{\circ}$ an $^{\circ}$ image $^{\circ}$ of ${ }^{\circ}$ the ${ }^{\circ}$ positive

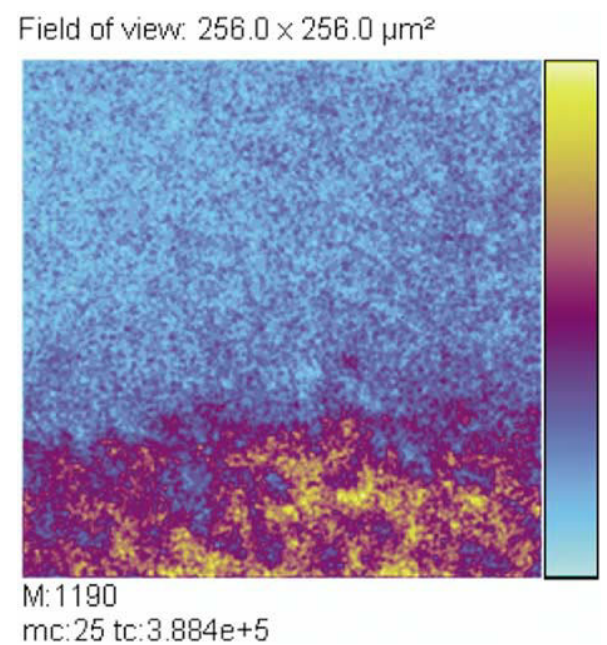

Figure 10. Negative secondary ion $(m / z$ 1190) image obtained under the irradiation of $\mathrm{Bi}_{5}^{2+}$ primary ions. The corpus callosum is on the bottom part of the images $(256 \times 256$ pixels, pixel size $1 \times$ $\left.1^{\circ} \mu \mathrm{m}^{2}\right)$. ${ }^{\circ}$ Same $^{\circ}$ data $^{\circ}$ acquisition $^{\circ}$ as $^{\circ}$ for ${ }^{\circ}$ Figure $^{\circ} 8 \mathrm{e}-\mathrm{f}$. 


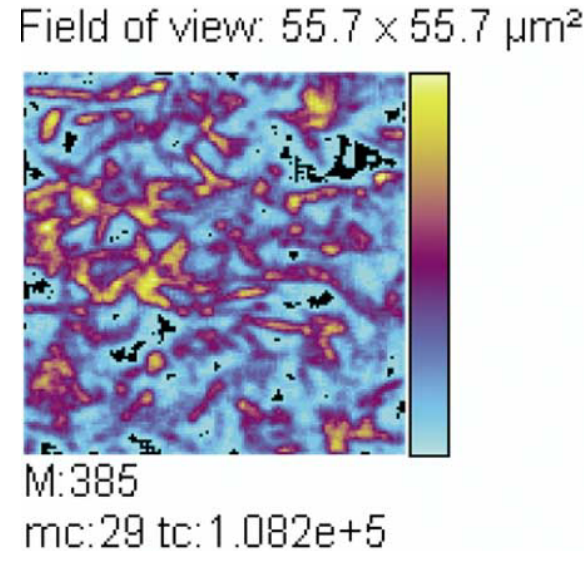

Figure 11. Positive secondary ion image of the cholesterol ions obtained inside the corpus callosum under the irradiation of $\mathrm{Bi}_{3}^{+}$ primary ions and with a primary ion dose density of $5 \cdot 10^{12}$ ions . $\mathrm{cm}^{-2}\left(128 \times 128\right.$ pixels, pixel size $\left.435 \times 435 \mathrm{~nm}^{2}\right)$.

secondary ions of cholesterol obtained inside the corpus callosum with a pixel size of only $435 \times 435 \mathrm{~nm}^{2}$ and with $\mathrm{Bi}_{3}^{+}$primary ions. The time necessary to obtain this image was less than $2 \mathrm{~min}$, and the primary ion dose density was $5 \times 10^{12}$ ions.cm ${ }^{-2}$. This pixel size was chosen to illustrate the values of the useful lateral resolution obtained with the same secondary ion species and in the same region of the brain.

\section{Conclusion}

The analytical potential of the new bismuth cluster LMIG has been explored using a model sample made of a rat brain tissue section analyzed without any preliminary washing or coating. It is shown that the increase of primary cluster ion intensity makes this ion source the most powerful when using $\mathrm{Bi}_{3}^{+}$or $\mathrm{Bi}_{5}^{2+}$. This source has better characteristics than the gold LMIG already used in TOF-SIMS biological imaging, mainly because of the increase of primary ion intensity. Although $\mathrm{Bi}_{3}^{+}$ and $\mathrm{Au}_{3}^{+}$can provide images of comparable quality, the data acquisition can be made more rapidly with $\mathrm{Bi}_{n}^{+}$ than with $\mathrm{Au}_{n}^{+}$. Furthermore, this ion source delivers doubly charged heavy ion beams such as those of $\mathrm{Bi}_{5}^{2+}$, which make it possible to reach a useful lateral resolution below $400 \mathrm{~nm}$. Under these conditions the recourse to any sample coating, which is done at the expense of the lateral resolution, is unnecessary. In other words, this new cluster primary ion source opens the possibility to obtain images of animal or human tissue sections under excellent analytical conditions, with reasonable acquisition times, at submicron spatial resolution and a mass range extended to more than $1000 \mathrm{Da}$. This method will be useful for a large variety of biological applications involving the localization of lipids, drugs, and metabolites. Furthermore, because the primary ion dose density can be maintained at a few $10^{9}$ ions $\cdot \mathrm{cm}^{-2}$, far below the static SIMS limit of $10^{13}$ ions $\cdot \mathrm{cm}^{-2}$, the damage induced to the surface can be considered to be negligible for a subsequent MALDI imaging, allowing complementary localization of peptides and proteins.

\section{Acknowledgments}

DT is indebted to the Institut de Chimie des Substances Naturelles (CNRS) for a Ph.D. research fellowship. Ion-TOF GmbH is gratefully acknowledged for providing the bismuth LMIG. Many thanks to Colin Helliwell (ION-TOF GmbH) for his assistance when reviewing this work and to Alfred Benninghoven (ION-TOF $\mathrm{GmbH}$ ) for fruitful discussions.

\section{References}

1. Caprioli, R. M.; Farmer, T. B.; Gile, J. Molecular Imaging of Biological Samples: Localization of Peptides and Proteins Using MALDI-TOF MS. Anal. Chem. 1997, 69, 4751-4760.

2. Chaurand, P.; Schwartz, S. A.; Caprioli, R. M. Profiling and Imaging Proteins in Tissue Sections by MS. Anal. Chem. 2004, 76, 87A-93A.

3. Spengler, B.; Hubert, M. Scanning Microprobe MatrixAssisted Laser Desorption Ionization (SMALDI) Mass Spectrometry: Instrumentation for Sub-Micrometer Resolved LDI and MALDI Surface Analysis. J. Am. Soc. Mass Spectrom. 2002, 13, 735-748.

4. Stoeckli, M.; Staab, D.; Staufenbiel, M.; Wiederhold, K. H.; Signor, L. Molecular Imaging of Amyloid $\beta$ Peptides in Mouse Brain Sections Using Mass Spectrometry. Anal. Biochem. 2002, 311, 33-39.

5. Rubakhin, S. V.; Greenough, W. T.; Sweedler, J. V. Spatial Profiling with MALDI MS: Distribution of Neuropeptides within Single Neurons. Anal. Chem. 2003, 75, 5374-5380.

6. Piyadasa, G.; McNabb, J. R.; Spicer, V.; Standing, K. G.; Ens, W. Imaging MALDI with an Orthogonal TOF Mass Spectrometer. Proceedings of the 52ndASMS Conference on Mass Spectrometry and Allied Topics; Nashville, TN, May 23-27, 2004.

7. Touboul, D.; Piednoël, H.; Voisin, V.; De La Porte, S.; Brunelle, A.; Halgand, F.; Laprévote, O. Changes of Phospholipid Composition within Dystrophic Muscle by MALDI-TOF-Mass Spectrometry and Mass Spectrometry-Imaging. Eur. J. Mass Spectrom. 2004, 10, 657-664.

8. Reyzer, M. L.; Hsieh, Y.; Ng, K.; Korfmacher, W. A.; Caprioli, R.M. Direct Analysis of Drug Candidates in Tissue by MatrixAssisted Laser Desorption/Ionization Mass Spectrometry. J. Mass Spectrom. 2003, 38, 1081-1092.

9. Belu, A. M.; Graham, D. J.; Castner, D. G. Time-of-flight Secondary Ion Mass Spectrometry: Techniques and Applications for the Characterization of Biomaterial Surfaces. Biomaterials 2003, 24, 3635-3653.

10. Pacholski, M. L.; Winograd, N. Imaging with Mass Spectrometry. Chem. Rev. 1999, 99, 2977-3005.

11. TOF SIMS: Surface Analysis by Mass Spectrometry; Vickerman, J.C.; Briggs, D., Eds.; IM Publications and Surface Spectra Ltd.: Manchester, UK, 2001.

12. Todd, P. J., Schaaff, T. G.; Chaurand, P.; Caprioli, R. M. Organic Ion Imaging of Biological Tissue with Secondary Ion Mass Spectrometry and Matrix-Assisted Laser Desorption/ Ionization. J. Mass Spectrom. 2001, 36, 355-369.

13. Roddy, T. P.; Cannon Jr., D. M., Meserole, C. A.; Winograd, N.; Ewing, A. G. Imaging of Freeze-Fractured Cells with in situ Fluorescence and Time-of-Flight Secondary Ion Mass Spectrometry. Anal. Chem. 2002, 74, 4011-4019.

14. Benguerba, M.; Brunelle, A.; Della-Negra, S.; Depauw, J.; Joret, H.; Le Beyec, Y.; Blain, M. G.; Schweikert, E. A.; Ben Assayag, G.; Sudraud, P. Impact of Slow Gold Cluster on Various 
Solids: Nonlinear Effects in Secondary Ion Emission, Nucl. Instrum. Methods Phys. Res. B 1991, 62, 8-22.

15. Touboul, D.; Halgand, F.; Brunelle, A.; Kersting, R.; Tallarek, E.; Hagenhoff, B.; Laprévote O. Tissue Molecular Ion Imaging by Gold Cluster Ion Bombardment. Anal. Chem. 2004, 76, 1550-1159.

16. Sjövall, P.; Jausmaa, J.; Johansson, B. Mass Spectrometric Imaging of Lipids in Brain Tissue. Anal. Chem. 2004, 76, 4271-4278.

17. Touboul, D.; Brunelle, A.; Halgand, F.; De La Porte, S.; Laprévote, O. Lipid Imaging by Gold Cluster Time-of-FlightSecondary Ion Mass Spectrometry: Application to Duchenne Muscular Dystrophy. J. Lipid Res. 2005, 46, 1388-1395.

18. Maarten Altelaar, A. F.; van Minnen, J.; Jiménez, C. R.; Heeren, R. M. A.; Piersma, S. R. Direct Molecular Imaging of Lymnaea stagnalis Nervous Tissue at Subcellular Spatial Resolution by Mass Spectrometry. Anal. Chem. 2005, 77, 735-741.

19. McDonnel, L.; Piersma, S. R.; Maarten Altelaar, A. F.; Mize, T. H.; Luxembourg, S. L.; Verhaert, P. D. E. M.; van Minnen, J., Heeren, R. M. A. Subcellular Imaging Mass Spectrometry of Brain Tissue. J. Mass Spectrom. 2005, 40, 160-168.

20. Nygren, H.; Malmberg, P.; Kriegeskotte, Ch.; Arlinghaus, H. F. Bioimaging TOF-SIMS: Localization of Cholesterol in Rat Kidney Sections. FEBS Lett. 2004, 566, 291-293.

21. Kollmer, F. Cluster Primary Ion Bombardment of Organic Materials. Appl. Surf. Sci. 2004, 231-232, 153-158.

22. TOF-SIMS IV product description-Sept. 2002, ION-TOF $\mathrm{GmbH}$, Mendelstr. 11, 48149 Muenster, Germany.
23. Sodhi, R. N. S. Time-of-Flight Secondary Ion Mass Spectrometry (TOF-SIMS): Versatility in Chemical and Imaging Surface Analysis. Analyst 2004, 129, 483-487.

24. Kötter, F.; Benninghoven, A. Secondary Ion Emission From Polymer Surfaces Under $\mathrm{Ar}^{+}, \mathrm{Xe}^{+}$and $\mathrm{SF}_{5}{ }^{+}$Ion Bombardment. Appl. Surf. Sci. 1998, 133, 47-57.

25. Standing, K. G.; Chait, B. T.; Ens, W.; McIntosh, G.; Beavis, R. Time-of-Flight Measurements of Secondary Organic Ions Produced by $1 \mathrm{keV}$ to $16 \mathrm{keV}$ Primary Ions. Nucl. Instrum. Methods Phys. Res. 1982, 198, 33-38.

26. Ziegler, J. F.; Biersack, J. P.; Littmark, H. The Stopping and Ranges of Ions in Solids; Pergamon Press: New York, 1985 (available at: www.srim.org).

27. Nagy, G.; Gelb, L. D.; Walker, A. V. An Investigation of Enhanced Secondary Ion Emission under $\mathrm{Au}_{n}{ }^{+}(n=1-7)$ Bombardment. J. Am. Soc. Mass Spectrom. 2005, 16, 733-742.

28. Brunelle, A.; Della-Negra, S.; Depauw, J.; Jacquet, D.; Le Beyec, Y.; Pautrat, M.; Baudin, K.; Andersen, H. H. Enhanced Secondary-Ion Emission under Gold-Cluster Bombardment With Energies From keV to MeV per Atom. Phys. Rev. A 2001, 63, 022902 1-10

29. Gilmore, I. S.; Seah, M. P. Electron Flood Gun Damage in the Analysis of Polymers and Organics in Time-of-Flight SIMS. Appl. Surf. Sci. 2002, 187, 89-100.

30. Paxinos, G.; Ch. Watson, C. H. The Rat Brain in Stereotaxic Coordinates, 4th ed. Academic Press: London, 1998. 